See Article page 2036.

\section{Commentary: Rapid deployment versus conventional tissue valves ... and the beat goes on}

\section{Nicholas T. Kouchoukos, MD}

Based on currently available data, the principal indications for use of rapid deployment (sutureless) aortic valve prostheses (RDV) remain incompletely defined. There is convincing evidence from single- and multi-institutional studies and from meta-analyses that, when compared with conventional bioprosthetic aortic valves for open aortic valve replacement, RDVs are associated with modest but significant reductions in the duration of cardiopulmonary bypass and aortic occlusion. ${ }^{1-6}$ Comparative observational studies, however, have also documented a greater prevalence of permanent pacemaker implantation with RDVs and no appreciable differences in early or mediumterm survival between the 2 valve types. ${ }^{2,3,5,6}$

In this issue of the Journal, White and colleagues ${ }^{7}$ compare the early and later outcomes of 590 propensitymatched patients undergoing aortic valve replacement with the LivaNova Percival $\mathrm{S}$ sutureless prosthesis $(\mathrm{n}=295)$, with any of 5 commercially available stented or stentless aortic bioprostheses $(n=295)$. The choice of a particular prosthesis was at the discretion of the operating surgeon, and no other selection criteria were reported. The cardiopulmonary bypass and aortic occlusion times were significantly shorter and the need for a permanent pacemaker was significantly greater among the patients in the RDV group. The rates of new-onset atrial fibrillation and acute kidney injury were significantly lower in the RDV group, but this did not result in shorter intensive care unit or hospital lengths of stay. There were no differences in early- and medium-term survival between the 2 groups. Rehospitalization rates for myocardial infarction, stroke,

\footnotetext{
From the Division of Cardiovascular and Thoracic Surgery, Missouri Baptist Medical Center, BJC Healthcare, St Louis, Mo.

Disclosures: The author reported no conflicts of interest.

The Journal policy requires editors and reviewers to disclose conflicts of interest and to decline handling or reviewing manuscripts for which they may have a conflict of interest. The editors and reviewers of this article have no conflicts of interest.

Received for publication June 26, 2020; revisions received June 26, 2020; accepted for publication June 26, 2020; available ahead of print July 12, 2020.

Address for reprints: Nicholas T. Kouchoukos, MD, Missouri Baptist Medical Center, 3023 N Ballas Rd, Suite 150D, St Louis, MO 63131 (E-mail: ntkouch@aol.com). J Thorac Cardiovasc Surg 2022;163:2043-4 $0022-5223 / \$ 36.00$

Copyright (c) 2020 by The American Association for Thoracic Surgery https://doi.org/10.1016/j.jtcvs.2020.06.093
}

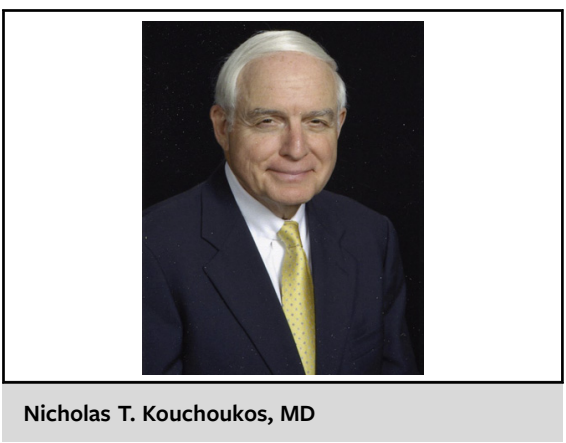

CENTRAL MESSAGE

Conclusive information

regarding which patients derive

substantial benefit from use of a

rapid deployment aortic valve is

lacking.

transient ischemic attack, and heart failure were substantially greater in the RDV group, although not all of the differences reached statistical significance. No information regarding postoperative antiplatelet or anticoagulation regimes was provided.

The study by White and colleagues ${ }^{7}$ does not provide information on which patients, if any, are likely to derive benefit from use of an RDV. Only 3\% of the patients had a previous open cardiac surgical procedure. Thirty percent of the patients in the study underwent a combined procedure, and separate analysis of this potentially greater-risk subgroup might have provided useful information on which patients would benefit from use of this prosthesis. In 2016, an International Expert Panel recommended that RDVs should be considered in patients with comorbidities, old age, calcified aortic roots, porcelain aortas, previous aortic homograft or stentless valve procedures, small aortic roots, and for combined procedures. ${ }^{8}$ With the exception of comorbidities and combined procedures, the prevalence of the remaining conditions was not documented in the study of White and colleagues. ${ }^{7}$ Until the results from prospective randomized trial become available (at least one is underway [PERSIST AVR trial, NCT02673697]), and given the shortterm complication rates and long-term detrimental effects of permanent pacemaker implantation on survival after surgical aortic valve replacement, ${ }^{9}$ uncertainty regarding longterm durability of RDVs, and information regarding relative costs, it seems prudent at present to restrict use of RDVs to patients with the aforementioned conditions. 


\section{References}

1. Pollari F, Santarpino G, Dell' Aquilla AM, Gazdag L, Alnahas H, Vogt F, et al. Better short-term outcome by using sutureless valves: a propensity-matched analysis. Ann Thorac Surg. 2014;98:611-6.

2. Phan K, Tsai YC, Niranjan N, Bouchard D, Carrel TP, Dapunt O, et al. Sutureless aortic valve replacement: a systematic review and meta-analysis. Ann Cardiothorac Surg. 2015;4:100-11.

3. Dalen M, Biancari F, Rubino AS, Santarpino G, Glaser N, De Praetere H, et al Aortic valve replacement through full sternotomy with a stented bioprosthesis versus minimally invasive sternotomy with a sutureless bioprosthesis. Eur J Cardiothorac Surg. 2016;49:220-7.

4. Rahmanian PB, Kaya S, Eghbalzadeh K, Menghesha H, Madershahian N, Wahlers T. Rapid deployment aortic valve replacement: excellent results and increased effective orifice areas. Ann Thorac Surg. 2018;105:24-30
5. Ensminger S, Fujita B, Bauer T, Mollmann H, Beckmann A, Bekeredjian R. Rapid deployment versus conventional prosthetic valve replacement for aortic stenosis. $J$ Am Coll Cardiol. 2018;71:1417-28.

6. Sohn SH, Jang M-J, Hwang HY, Kim KH. Rapid deployment or sutureless valve versus conventional bioprosthetic aortic valve replacement: a meta-analysis. $J$ Thorac Cardiovasc Surg. 2018:155:2402-12.

7. White A, Bozso SJ, Lahey O, Hong Y, Wang S, Nagendran J, et al. Rapid deployment valves versus conventional tissue valve for aortic valve replacement. $J$ Thorac Cardiovasc Surg. 2022;163:2036-42.

8. Gersak B, Fischlein T, Folliguet TA, Meuris B, Teoh KHT, Moten SC, et al. Sutureless, rapid deployment valves and stented bioprosthesis in aortic valve replacement: recommendations of an international expert consensus panel. Eur $J$ Cardiothorac Surg. 2016;49:709-18.

9. Greason KL, Lahr BD, Stulak JM, Cha Y-M, Rea RF, Schaff HV, et al. Long-term mortality effect of early pacemaker implantation after surgical aortic valve replacement. Ann Thorac Surg. 2017;104:1259-64.

\section{Commentary: Defining the role for rapid deployment valves in aortic valve disease}

\author{
Peter J. Altshuler, MD, and Pavan Atluri, MD
}

As cardiac surgery evolves with minimally invasive technology, defining a therapy's precise role in achieving better patient outcomes is paramount to its utility. Rapid deployment valves (RDVs) represents 1 such technology attempting to find its niche in the surgical management of aortic valve pathology. RDVs fall between conventional surgical repair of aortic valves and transcatheter aortic valve replacement; sutureless replacement offers quicker implantation time in open repair while allowing for resection or modification of diseased tissue not afforded in transcatheter-based therapy. Retrospective reviews and meta-analyses have demonstrated shorter cardiopulmonary

From the Division of Cardiovascular Surgery, Department of Surgery, University of Pennsylvania, Philadelphia, Pa.

Disclosures: The authors reported no conflicts of interest.

The Journal policy requires editors and reviewers to disclose conflicts of interest and to decline handling or reviewing manuscripts for which they may have a conflict of interest. The editors and reviewers of this article have no conflicts of interest.

Received for publication June 29, 2020; revisions received June 29, 2020; accepted for publication June 29, 2020; available ahead of print July 11, 2020.

Address for reprints: Pavan Atluri, MD, Division of Cardiovascular Surgery, Department of Surgery, Hospital of the University of Pennsylvania, 3400 Spruce St, 6 Silverstein, Philadelphia, PA 19104 (E-mail: pavan.atluri@pennmedicine.upenn. edu).

J Thorac Cardiovasc Surg 2022;163:2044-5

0022-5223/\$36.00

Copyright (c) 2020 by The American Association for Thoracic Surgery

https://doi.org/10.1016/j.jtcvs.2020.06.087

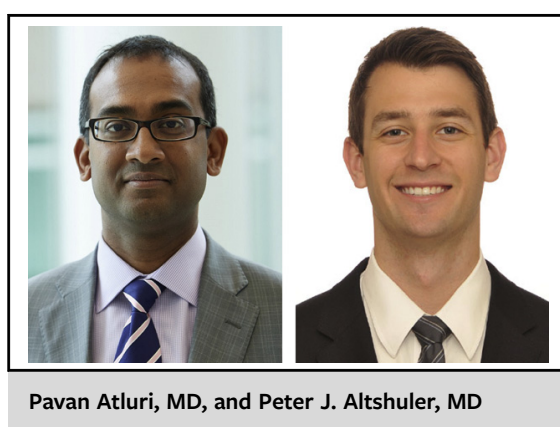

CENTRAL MESSAGE

Further studies are needed to identify specific indications for rapid deployment valve use over conventional valve replacement techniques in treating aortic valve disease.

bypass times in RDVs compared with conventional open repair but have noted significantly greater rates of conduction disorders requiring pacemaker insertion. ${ }^{1,2}$ Conversely, RDV use compared with transcatheter aortic valve replacement has shown diminished rates of paravalvular leaks and improved 30-day survival but increased rates of in-hospital complications.

White and colleagues ${ }^{4}$ attempt to better identify the precise role for RDVs through their own retrospective institutional experience with the Perceval S (Sorin Group Italia Srl, Saluggia, Italy) RDV compared with conventional tissue repair. After normalizing groups through inverse 